\title{
Early Development of the Thalamic Inhibitory Feedback Loop in the Primary Somatosensory System of the Newborn Mice
}

\author{
Alexis Evrard and Nicole Ropert \\ INSERM, Unité 603, Centre National de la Recherche Scientifique, UMR 8154, and Laboratory of Neurophysiology and New Microscopies, Université Paris \\ Descartes, 75006 Paris, France
}

\begin{abstract}
Spontaneous neuronal activity plays an important role during the final development of the brain circuits and the formation of the primary sensory maps. In young rats, spindle bursts have been recorded in the primary somatosensory cortex. They are correlated with spontaneous muscle twitches and occur before active whisking. They bear similarities with the spindles recorded in adult brain that occur during early stages of sleep and rely on a thalamic feedback loop between the glutamatergic nucleus ventroposterior medialis (nVPM) and the GABAergic nucleus reticularis thalami (nRT). However, whether a functional nVPM-nRT loop exists in newborn rodents is unknown. We studied the reciprocal synaptic connections between $\mathrm{nVPM}$ and $\mathrm{nRT}$ in thalamic acute slices from mice from birth [postnatal day 0 (P0)] until P9. We first demonstrated that nVPM-to-nRT EPSCs could be distinguished from corticothalamic EPSCs by their inhibition by 5-HT attributable to the transient expression of functional presynaptic serotonin 1B receptors. The nVPM-to-nRT EPSCs and nRT-to-nVPM IPSCs were both detected the first day after birth; their amplitude near $2 \mathrm{nS}$ was relatively stable until P5. At P6 -P7, there was a rapid and simultaneous increase of both nVPM-to-nRT EPSCs and nRT-to-nVPM IPSCs that reached 8 and $9 \mathrm{nS}$, respectively. Our results show that the thalamic synapses implicated in spindle activity are functional shortly after birth, suggesting that they could already generate spindles during the first postnatal week. Our results also suggest an inhibitory action of 5-HT on the spindle bursts of the newborn mice.
\end{abstract}

\section{Introduction}

The primary somatosensory (S1) maps of the mouse whiskers (Woolsey and Van der Loos, 1970) are a critical model to elucidate the mechanisms of sensory map development and neuronal circuit refinement. They emerge sequentially during the first postnatal week as barrelettes in brainstem, barreloids in thalamic nucleus ventralis posterior medialis (nVPM), and barrels in S1 cortex (Belford and Killackey, 1979b; Killackey and Belford, 1979).

After early sensory deprivation, S1 maps (Van der Loos and Woolsey, 1973; Belford and Killackey, 1979a, 1980; Jeanmonod et al., 1981), cortical responses to whisker stimulation (Simons and Land, 1987; Rema et al., 2003; Shoykhet et al., 2005; Lee et al., 2007), and tactile discrimination (Carvell and Simons, 1996) are abnormal, demonstrating the importance of neuronal activity for morphological and functional development of S1 maps. Genetic studies also showed that glutamate and serotonin (5-HT) are key neurotransmitters for S1 map development (Crair, 1999; Erzurumlu and Kind, 2001; Gaspar et al., 2003; Inan and Crair, 2007).

Received April 7, 2009; revised June 30, 2009; accepted July 5, 2009.

This work was supported by INSERM, Centre National de la Recherche Scientifique, Fondation Bettencourt Schueller, and by a grant from Agence Nationale de la Recherche Neurosciences, Neurologie, et Neuropsychiatrie Grant A05189KS. We thank Etienne Audinat, Serge Charpak, and Martin Oheim for critical comments on this manuscript.

Correspondence should be addressed to Nicole Ropert, Laboratoire de Neurophysiologie et Nouvelles Microscopies, INSERM U603, CNRS UMR 8154, Université Paris Descartes, 45 rue des Saints-pères, 75006 Paris, France. E-mail: nicole.ropert@parisdescartes.fr.

D0I:10.1523/JNEUROSCI.1671-09.2009

Copyright (C) 2009 Society for Neuroscience $\quad$ 0270-6474/09/299930-11\$15.00/0
A complete inactivation of NMDA receptors (NMDARs) disrupts all S1 maps (Li et al., 1994; Iwasato et al., 1997, 2000). The cortical NMDARs that mediate Hebbian plasticity at the thalamocortical (TC) synapses (Crair and Malenka, 1995; Feldman et al., 1998; Lu et al., 2001) control the differentiation of cortical spiny stellate neurons and the clustering of the TC axonal arbors (Iwasato et al., 2000; Datwani et al., 2002b; Lee et al., 2005). The presynaptic $5-\mathrm{HT}_{1 \mathrm{~B}}$ receptors $\left(5-\mathrm{HT}_{1 \mathrm{~B}} \mathrm{Rs}\right)$ that inhibit glutamate release at the TC synapse (Laurent et al., 2002) control also barrel development (Cases et al., 1996; Salichon et al., 2001). However, several cortex-specific genetic modifications have no effect on the closure of the critical period (Lu et al., 2001; Datwani et al., 2002a; Rebsam et al., 2005; Inan et al., 2006; Iwasato et al., 2008) and the TC axon clustering (Iwasato et al., 2000; Hannan et al., 2001; Inan et al., 2006; Watson et al., 2006), suggesting that still unknown changes occur in the thalamus.

Active whisking behavior emerges at 2 weeks (Landers and Philip Zeigler, 2006), after the S1 map formation, suggesting that, as in the visual system (Huberman et al., 2008), early spontaneous activity contributing to S1 map development may be generated before active whisking. Interestingly spontaneous $10 \mathrm{~Hz}$ spindles were recorded in newborn rat S1 cortex (Khazipov et al., 2004). Their intrinsic frequency is unaffected by GABAergic antagonists applied in S1 cortex (Minlebaev et al., 2007, 2009), and they are correlated with nVPM neuronal activity (Khazipov et al., 2004), suggesting that they are generated in the thalamus and that they bear similarities with the adult cortical $7-15 \mathrm{~Hz}$ spindles. The adult spindles are generated during early stages of sleep by a 

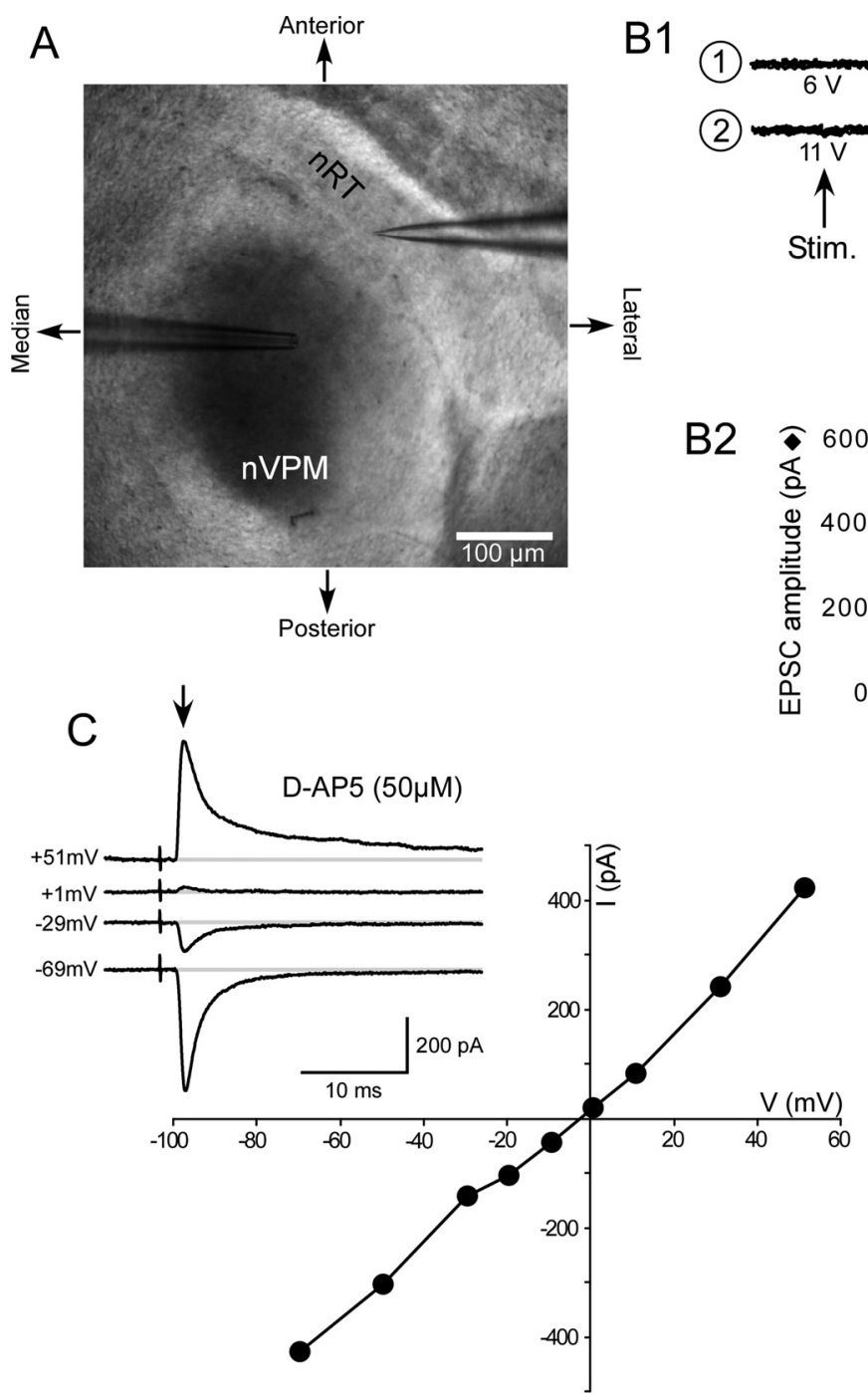

B1
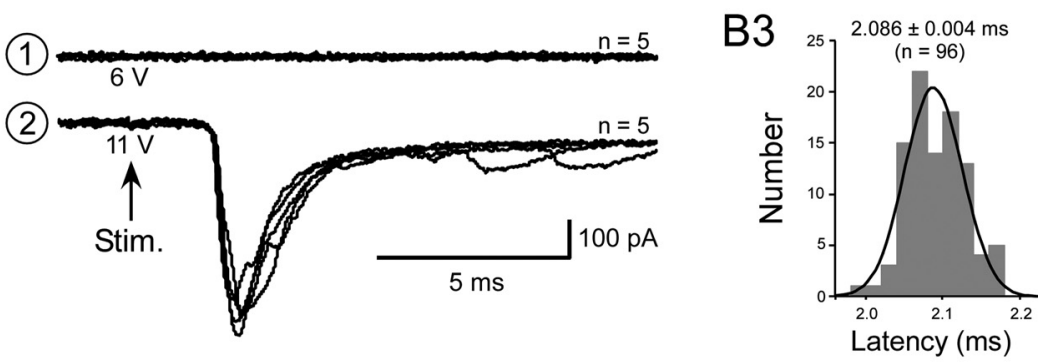
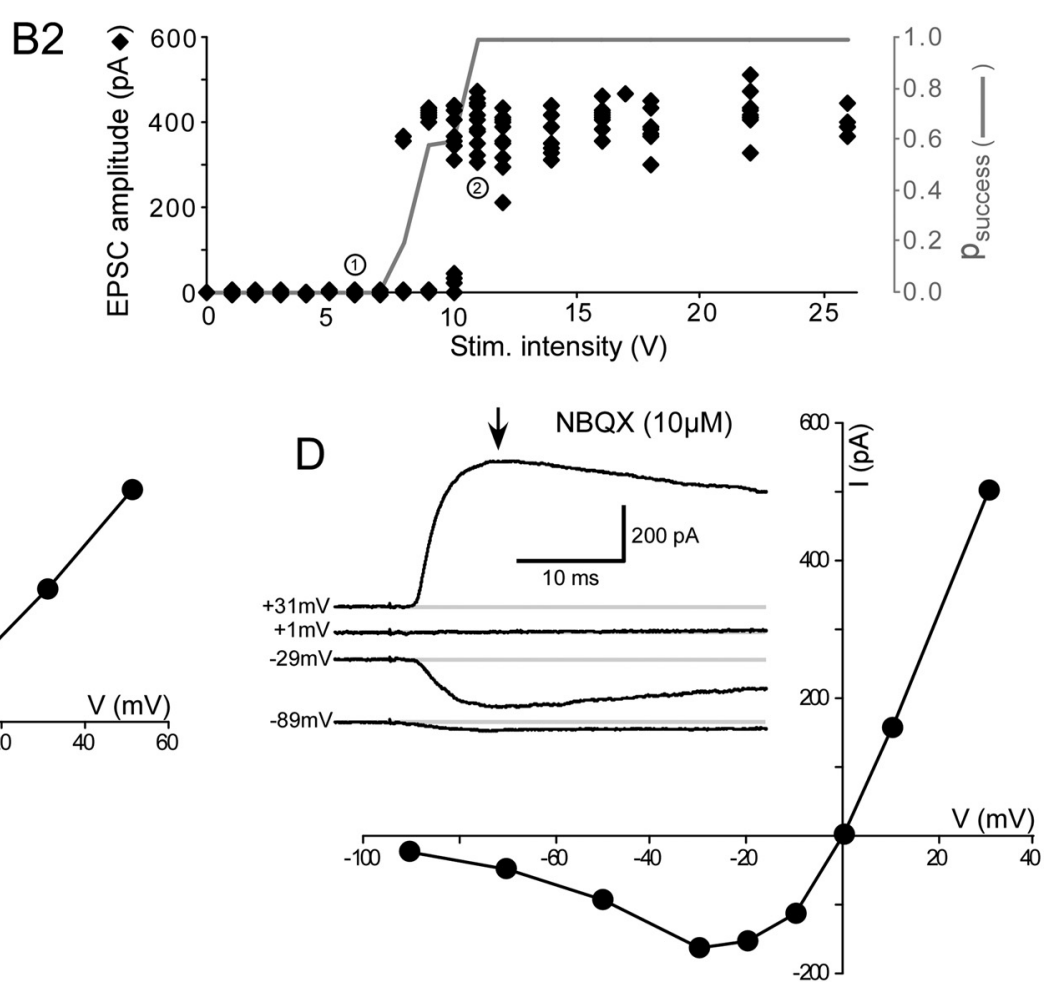

Figure 1. Electrical nVPM stimulation evokes monosynaptic unitary EPSCs in nRT. $A$, View of a horizontal thalamic slice using infrared video microscopy and showing a recording patch pipette in the nRT, and a stimulating theta pipette in the nVPM. $\boldsymbol{B}$, Example of a minimal unitary fast inward EPSC at P7. Superimposed $(n=5)$ EPSCs evoked by subthreshold (1) and suprathreshold (2) stimulation (B1). Superimposed graphs (B2) illustrating for the same cell, the changes with stimulation intensity $(0-26 \mathrm{~V})$ of the peak amplitude of individual EPSCs (black diamond; $n=8-15$ ), and the probability of response (gray line). Minimal unitary EPSCs of relatively stable amplitude near $400 \mathrm{pA}$ and without transmission failure between 11 and $26 \mathrm{~V}$. B3, Same cell, latency distribution of EPSCS $(n=96)$ evoked at $11-26 \mathrm{~V}$ and fitted with a single Gaussian function (mean of $2.086 \pm 0.004 \mathrm{~ms}$ ). C, Linear $/-V$ curve of a fast AMPAR-mediated EPSC recorded in the presence of $50 \mu \mathrm{m}$ D-AP-5, with a reversal at $-1.54 \mathrm{mV}$. Inset, Same cell, average $(n=4-5)$ EPSCs at $+51,+1,-29$, and $-69 \mathrm{mV} . \boldsymbol{D}, I-V$ curve of an NMDAR-mediated EPSC in the presence of $10 \mu \mathrm{m}$ NBQX with a reversal at $-0.8 \mathrm{mV}$ and a typical blockade at potentials more negative than $-10 \mathrm{mV}$. Inset, Same cell, average $(n=4-5)$ EPSC at $+31,+1,-29$, and $-89 \mathrm{mV}$.

thalamic inhibitory feedback loop between the GABAergic nucleus reticularis thalami (nRT) and the glutamatergic nVPM (Fuentealba and Steriade, 2005). So far, there has been no systematic investigation of this intrathalamic circuitry during the first postnatal week; therefore, we investigated the development of the reciprocal nVPM-nRT synaptic connections in the newborn mice.

\section{Materials and Methods}

Animals. Experiments were performed on newborn mice [postnatal day 0 (P0) to P9, with P0 being the day of birth] NMRI mice (Janvier) born in the local animal house. Controls were performed in older mice (P18P23). All experiments followed the European Union and institutional guidelines for the care and use of laboratory animals (Council Directive 86/609EEC).

Slice preparation. Animals were anesthetized by intraperitoneal injection of pentobarbital $(20 \mathrm{mg} / \mathrm{kg})$ and decapitated. The brain was quickly removed and placed in ice-cold $\left(2-4^{\circ} \mathrm{C}\right)$ oxygenated $\left(5 \% \mathrm{O}_{2}, 95 \% \mathrm{CO}_{2}\right)$ standard artificial CSF (ACSF). Horizontal slices were cut (thickness, 400 $\mu \mathrm{m}$ at $\mathrm{P} 0-\mathrm{P} 11 ; 300 \mu \mathrm{m}$ at $\mathrm{P} 18-\mathrm{P} 23)$ using a vibratome (VT100S; Leica). The slices were first maintained during $1 \mathrm{~h}$ at $33^{\circ} \mathrm{C}$ and later at room temperature $\left(22-24^{\circ} \mathrm{C}\right)$ in oxygenated standard ACSF.

Electrophysiological recordings. For recording, the slices were placed in a small $(\sim 1 \mathrm{ml})$ chamber, perfused at $2 \mathrm{ml} / \mathrm{min}$ with ACSF at physiological temperature $\left(33-34^{\circ} \mathrm{C}\right)$, and maintained stable using a V-shaped piece of platinum. Recordings were obtained from either the nRT or the nVPM identified under visual control using an upright fixed-stage microscope (Axioskop FS; Carl Zeiss) with Nomarski optics equipped with a camera (Cascade 512B; Roper Scientific). Somatic whole-cell recordings were performed using borosilicate glass pipettes with a tip resistance of 2-3 M $\Omega$ and an Axopatch 200B amplifier (Molecular Devices). Membrane capacitance and serial resistance were not compensated. Voltage and current signals were filtered at $5 \mathrm{kHz}$, digitized at $100 \mathrm{kHz}$ using a digital board (Digidata 1322A; Molecular Devices), and stored on computer. The protocols were generated using the program pClamp10 (Molecular Devices). The series resistance $\left(R_{\mathrm{s}}\right)$ was estimated using a short-duration $(20 \mathrm{~ms})$ negative voltage step $(3 \mathrm{mV})$ preceding by $200 \mathrm{~ms}$ the electrical stimulation of the afferent fibers. Typical $R_{\mathrm{s}}$, calculated at 
the beginning of the current step using Ohm's law, were of the order of 5-20 M $\Omega$, and recordings were discarded when $R_{\mathrm{s}}$ increased by $>20 \%$ of the control value. Afferent fibers were stimulated with a bipolar extracellular electrode, by applying voltage steps with an isolated voltage stimulator (DS2A; Digitimer). The voltage steps were applied through a theta-glass pipette filled with standard ACSF and positioned in the $\mathrm{nVPM}$ or $\mathrm{nRT}$. In several cases, activation of the somatodendritic region of the nVPM neurons was obtained by a short-duration (10 $\mathrm{ms})$ pressure $(\sim 450 \mathrm{mbar})$ pulse of glutamate (100 $\mu \mathrm{M}$ in standard ACSF) using a patch pipette (tip diameter, $\sim 2-3 \mu \mathrm{m}$ ).

The recorded neurons were maintained in voltage-clamp mode using whole-cell patchclamp recording. A low-frequency $(0.03 \mathrm{~Hz})$ extracellular stimulation was used to record stable control responses. The minimal singleafferent fiber stimulation intensity was found by progressively increasing the intensity until a plateau response was obtained (Fig. 1) that remained stable when the intensity was further increased and that correspond to an absence of action potential failure in the afferent fiber. The stimulation intensity was set $\sim 5 \mathrm{~V}$ above the intensity necessary to avoid action potential failures in the afferent fibers.

The data were analyzed offline using Clampex (Molecular Devices), Excel (Microsoft), and Igor Pro 4.1 (WaveMetrics). Current-voltage $(I-V)$ curves of the evoked postsynaptic currents (PSCs) were obtained by plotting the PSC amplitude against the membrane potential (between -90 and $+50 \mathrm{mV}$ for the EPSC and -110 and $+30 \mathrm{mV}$ for the IPSC). The amplitude of the $\mathrm{GABA}_{\mathrm{A}}$ receptor $\left(\mathrm{GABA}_{\mathrm{A}} \mathrm{R}\right)$-mediated IPSCs was measured at their peak. The amplitude of the AMPA receptor (AMPAR)-mediated component of the EPSCs was measured at the time of their peak at $-70 \mathrm{mV}$. The amplitude of the NMDAR component of the EPSCs was measured $10 \mathrm{~ms}$ after the beginning of the stimulation artifact. The PSC conductance was calculated by dividing the PSC amplitude by the PSC driving force (70 mV for EPSCs, $63 \mathrm{mV}$ for IPSCs). The coefficient of variation (CV) of the PSC amplitude was estimated using only the successful responses by dividing the SD by the mean of the response amplitude. Paired-pulse ratios (PPRs) were obtained by applying two stimulations at $50 \mathrm{~ms}$ interval and calculated as the second PSC amplitude divided by the first PSC amplitude (PSC2/PSC1). Control PSC amplitudes were measured in standard ACSF for at least $10 \mathrm{~min}$ to control the stability of the response before the application of drugs. In a preliminary study, we showed that a delay of $\sim 3$ min was observed between the beginning of NBQX application and the complete inhibition of the EPSCs (data not shown). Effects of drugs on the PSC amplitude were expressed as percentage of control amplitude. The PSC latencies were defined as the time when the PSCs reach $10 \%$ of their peak amplitude. The EPSC rise time (RT) was the time between 10 and 90\% maximal amplitude; the IPSC RT was the time between 20 and $80 \%$ maximal amplitude, the slower RT of the IPSCs being more affected by the background noise. The duration of PSCs was measured as the half-amplitude duration $\left(\Delta t_{1 / 2}\right)$.

Statistical analyses were performed using GraphPad InStat (GraphPad Software). Data are given as mean \pm SEM. The significance was calculated using ANOVA, unpaired or paired Student's $t$ test, when appropriate.

Solutions and drugs. All chemicals were supplied by Sigma unless otherwise specified. Standard ACSF contained the following (in mM): $126 \mathrm{NaCl}$, $2.85 \mathrm{KCl}, 1.25 \mathrm{KH}_{2} \mathrm{PO}_{4}, 1.5 \mathrm{MgSO}_{4}, 2 \mathrm{CaCl}_{2}, 26 \mathrm{NaHCO}_{3}$, and 10 glucose.
The following compounds were bath applied: 5-HT (5-20 $\mu \mathrm{M})$, CP93129 [1,4-dihydro-3-(1,2,3,6-tetrahydro-4-pyridinyl)-5H-pyrro-1-[3,2-b]pyridin5-one dihydrochloride] (100 nM; Tocris Biosciences), GR127935 ( $N$-[4methoxy-3-(4-methyl-1-piperazinyl)phenyl]-2' -methyl-4' -(5-methyl1,2,4- oxadiazol-3-yl)-1,1'-biphenyl-4-carbox amide hydrochloride) (100 nM; Tocris Biosciences), D-(-)-2-amino-5-phosphonopentanoic acid (D-AP-5) (50 $\mu \mathrm{M}$; Ascent Scientific), 2,3-dioxo-6-nitro-1,2,3,4tetrahydrobenzo $[f]$ quinoxaline-7-sulfonamide disodium salt (NBQX) (10 $\mu \mathrm{M}$; Ascent Scientific), gabazine [6-imino-3-(4-methoxyphenyl)$1(6 \mathrm{H})$-pyridazinebutanoic acid hydrobromide] (10 $\mu \mathrm{M}$; Ascent Scientific).

The intracellular pipette solution contained the following (in mM): 120 Cs methylsulfate, $10 \mathrm{CsCl}, 10 \mathrm{HEPES}, 4 \mathrm{~K}-\mathrm{ATP}, 2 \mathrm{MgCl}_{2}, 0.4 \mathrm{Na}-\mathrm{GTP}$, and 0.2 EGTA, pH adjusted to 7.35 using $\mathrm{CsOH}$. All voltage values were corrected for a $-9 \mathrm{mV}$ liquid junction potential.

\section{Results}

Electrical stimulation of nVPM evokes two types of EPSC in nRT of young mice

Somatic whole-cell recordings were performed from the GABAergic neurons of the $\mathrm{nRT}$ identified under infrared video microscopy by their location between the nVPM and the internal capsule (IC) and by the orientation of their dendritic tree parallel 

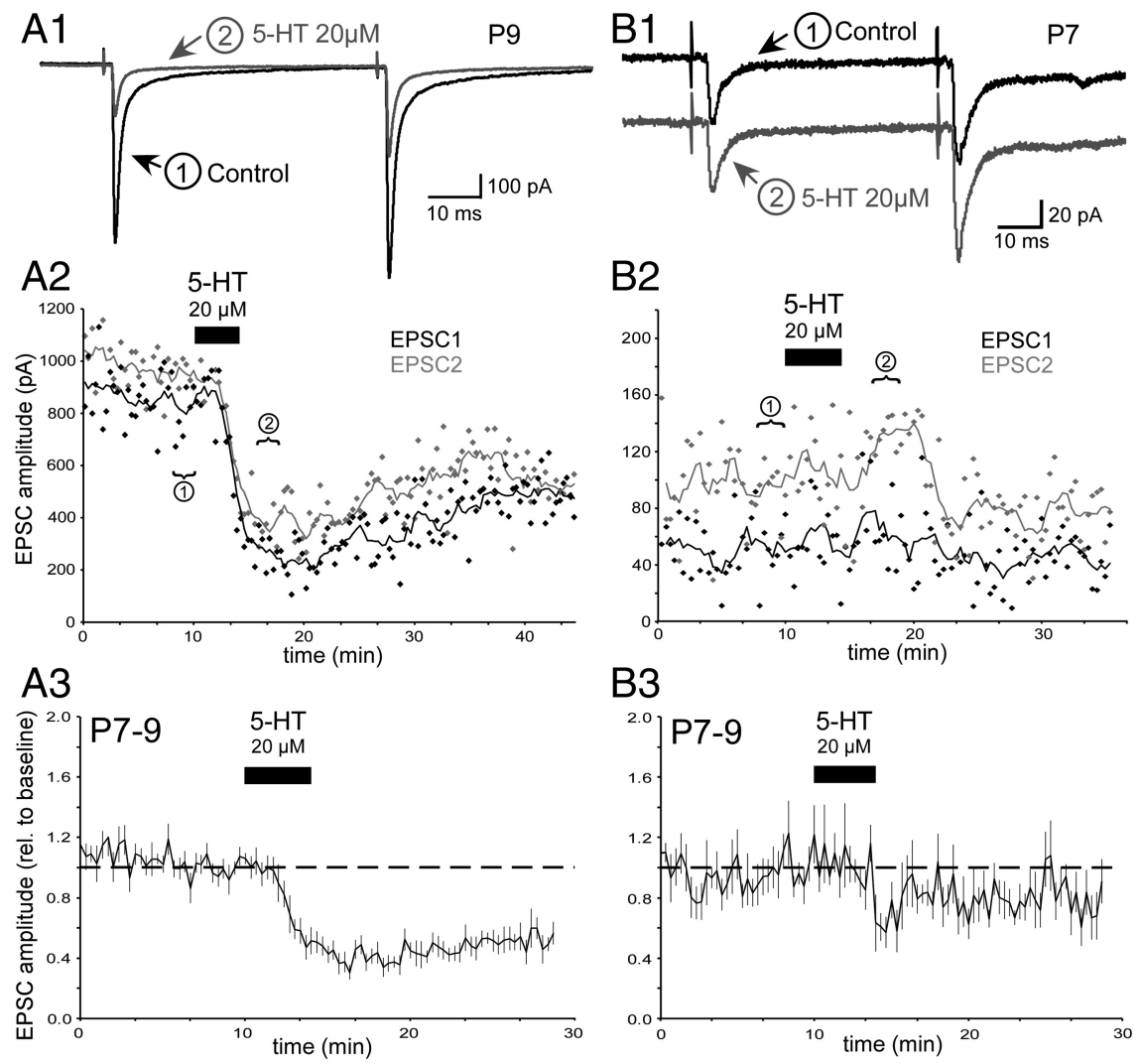

B3
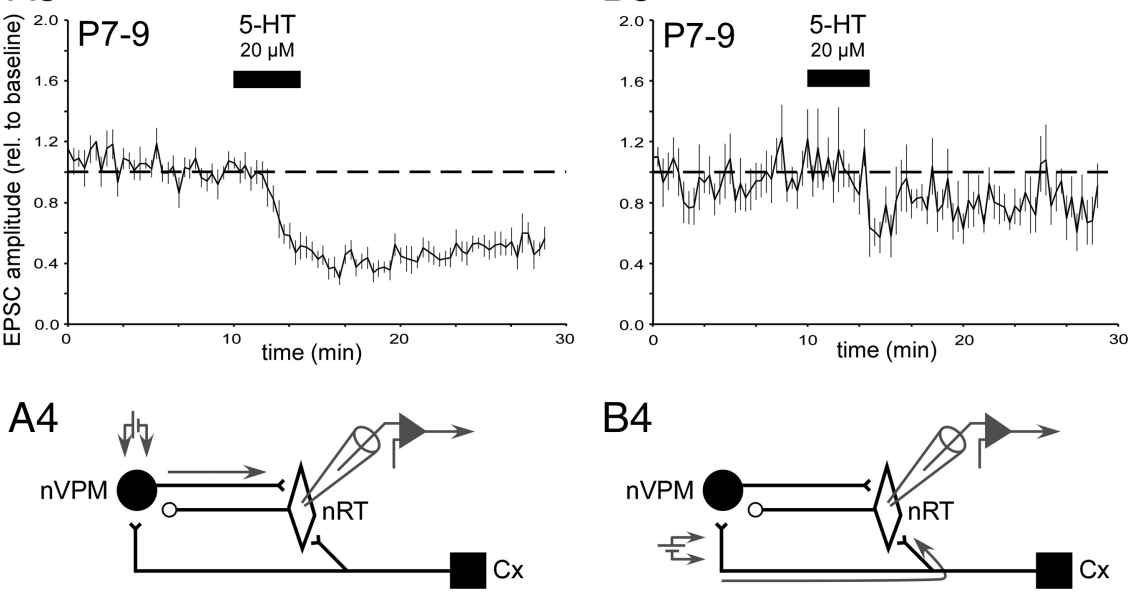

Figure 3. Inhibitory effect of 5-HT on electrically evoked nVPM-to-nRT EPSCs in nRT at P7-P9. A1, A2, Example of a 5-HTsensitive nVPM-to-nRT EPSC in nRT at P9 ( $-70 \mathrm{mV}$ holding potential). A1, Average $(n=6)$ unitary EPSCs recorded in $n R T$ in response to paired pulse (50 ms interval) electrical stimulation of nVPM, in control (black trace), and during $20 \mu \mathrm{m} 5$-HT (gray trace). In control, the first EPSC (EPSC1) amplitude is smaller than the second (EPSC2), with a PPR (EPSC2/EPSC1) of 1.34. The 5-HT application induced a reduction of EPSC1 amplitude to $72 \%$ of its control value; with EPSC2 being less affected, the PPR increased to 1.90. A2, Time course of inhibitory effect of 5-HT on EPSC1 (black) and EPSC2 (gray) amplitude. Dots are individual responses, and lines are running averages $(n=4)$. At the end of the application, the effect of 5 -HT has reached its maximum. The average responses shown in $\mathbf{A} 1$ were obtained at times 1 for control and 2 for 5 -HT. Washing 5-HT for 25 min induced a partial recovery. A3, Average ( $n=6$ cells) time course of the effect of 5-HT on EPSC1 amplitude of 5-HT-sensitive responses recorded at P7-P9. A4, Schematic diagram of the connection (gray arrow) responsible for the 5-HT-sensitive unitary EPSCs evoked by nVPM stimulation. B1, B2, Example of a 5-HT-insensitive unitary L6CX-to-nRT EPSC in nRT at P7 ( $-70 \mathrm{mV}$ holding potential). B2, Average $(n=6)$ unitary EPSCs recorded in $\mathrm{nRT}$ in response to paired pulse (50 ms interval) electrical stimulation of $n V P M$. The amplitude of both EPSC1 and EPSC2 were not significantly different in control (black trace) and during bath application of 5-HT (gray trace). B2, The bath application of $20 \mu \mathrm{m} 5$-HT had no significant effect on EPSC1 (black) and EPSC2 (gray) amplitude. Dots are individual responses, and lines are running averages $(n=4)$. B3, Average ( $n=10$ cells) EPSC1 amplitude of 5-HT-insensitive responses recorded at P7-P9. B4, Schematic diagram of connection (gray arrow) responsible for the 5-HT-insensitive unitary L6CX-to-nRT EPSCs evoked by nVPM stimulation. CX, Cortex.

to the IC. Neurons were voltage clamped near their resting membrane potential (RMP) at $-70 \mathrm{mV}$. Low-frequency $(0.03 \mathrm{~Hz})$ minimal electrical stimulations of the nVPM (see Materials and Methods) were used to evoke stable single fiber unitary EPSCs in nRT neurons (Fig. 1).

The nRT receives two excitatory inputs. The first nVPM-tonRT input that originates in the nVPM sends axon collaterals in $\mathrm{nRT}$ and innervates the barrel cortex. The second input originates in the layer 6 barrel cortex (L6Cx), and sends axon collaterals in the nRT before invading the nVPM (Bourassa et al., 1995; Liu et al., 2001; Gentet and Ulrich, 2003, 2004). The electrical stimulation of nVPM can activate both the somatodendritic region of the nVPMto-nRT relay neurons and the axonal endings of the corticothalamic fibers that have already invaded the nVPM during the first postnatal week (Jacobs et al., 2007). Recordings were first performed during a restricted period of development (P7-P9) to investigate the possibility to discriminate nVPM-to-nRT and L6Cxto-nRT EPSCs at $-70 \mathrm{mV}$.

The minimal nVPM stimulation (Fig. 2D2) evoked fast AMPAR-mediated EPSCs with a wide range of amplitude (range, 20-1400 pA; mean \pm SEM, $430.0 \pm 55.2 \mathrm{pA} ; n=46)$. They had a short latency $(1.96 \pm 0.08 \mathrm{~ms} ; n=46)$ with a single Gaussian distribution, as expected for monosynaptic responses (Fig. 1B3). The EPSCs recorded at $-70 \mathrm{mV}$ had a rapid 10-90\% RT $(0.55 \pm 0.04 \mathrm{~ms}$; $n=46)$ and a short $\Delta t_{1 / 2}(1.69 \pm 0.12 \mathrm{~ms}$; $n=46)$. Their linear $I-V$ curve with a reversal potential at $0.93 \pm 2.05 \mathrm{mV}(n=$ 6) was isolated in the presence of $50 \mu \mathrm{M}$ NMDAR antagonist D-AP-5 (Fig. 1C), and they were blocked by the AMPA/kainate receptor antagonist NBQX $(10 \mu \mathrm{M})$. In control, a slow NMDAR-mediated component with a typical NMDAR $I-V$ curve and a reversal potential at $0.67 \pm$ $0.85 \mathrm{mV}(n=6)$ was also recorded. It persisted in the presence of $10 \mu \mathrm{M}$ NBQX (Fig. $1 D$ ), and it was blocked by $50 \mu \mathrm{M}$ D-AP-5. In few experiments (4 of 32), the minimal nVPM stimulation evoked a late polysynaptic $\mathrm{GABA}_{\mathrm{A}} \mathrm{R}$-mediated IPSC that reversed near $-60 \mathrm{mV}$, a value close to the chloride equilibrium potential $\left(E_{\mathrm{Cl}}^{-}\right)$ in our recording conditions, which was inhibited by $10 \mu \mathrm{M} \mathrm{GABA}_{\mathrm{A}} \mathrm{R}$ antagonist gabazine (data not shown). Such experiments were excluded from our analysis.

Together, these results indicate that the monosynaptic responses evoked by the VPM electrical stimulation were glutamatergic EPSCs. Their wide range of amplitude (Fig. 2D2) suggests that the nVPM electrical stimulation can evoke both nVPM-to-nRT and L6Cx-to-nRT EPSCs. To selectively activate the somatodendritic region of $\mathrm{nVPM}$-to-nRT relay neurons, we used focal pulses of glutamate $(100 \mu \mathrm{M})$ in the nVPM (Fig. 2) and evoked bursts of EPSCs with fast kinetics $\left(10-90 \% \mathrm{RT}=0.45 \pm 0.01 \mathrm{~ms} ; \Delta t_{1 / 2}=2.00 \pm 0.23 \mathrm{~ms} ; n=\right.$ 12) and large amplitude, with the first EPSC in the burst being always larger than $100 \mathrm{pA}(140-640 \mathrm{pA} ; 344.1 \pm 44.7 \mathrm{pA} ; n=$ $12)$. The distribution of the $\mathrm{NP} M$ regions from which glutamate pulses evoked EPSC bursts in the nRT indicates a precise spatial relationship between nVPM and nRT (Fig. 2 A), similar to that found for pairs of monosynaptically connected neurons in juvenile (P14-P20) rats (Gentet and Ulrich, 2003). Our results suggest that the extracellular stimulation of the 
Table 1. Physiological characteristics of the postsynaptic currents in P1-P9 mice

\begin{tabular}{|c|c|c|c|c|c|c|}
\hline & \multicolumn{3}{|l|}{ nVPM-to-nRT EPSCs } & \multirow{3}{*}{$\begin{array}{l}\text { L6CX-to-nRT EPSCs } \\
\text { Electrically evoked } \\
5 \text {-HT-insensitive EPSC } \\
\text { P7-P9 }(n=10)\end{array}$} & \multirow{2}{*}{\multicolumn{2}{|c|}{ nRT-nVPM IPSCs Electrically evoked IPSC }} \\
\hline & \multicolumn{2}{|c|}{ Electrically evoked 5-HT-sensitive EPSC } & \multirow{2}{*}{$\begin{array}{l}\text { Glutamate-evoked } \\
5 \text {-HT-sensitive EPSC } \\
\text { P7-P9 }(n=12)\end{array}$} & & & \\
\hline & $\mathrm{P} 1-\mathrm{P} 5(n=22)$ & P7-P9 $(n=14)$ & & & $\mathrm{P} 1-\mathrm{P} 5(n=18)$ & $\mathrm{P} 7-\mathrm{P} 9(n=21)$ \\
\hline Conductance (nS) & $2.08 \pm 0.31^{* * * a}$ & $7.76 \pm 1.13$ & $4.92 \pm 0.64$ & $0.65 \pm 0.08^{* * * b}$ & $1.77 \pm 0.36^{* * * c}$ & $9.41 \pm 1.64$ \\
\hline CV & $0.22 \pm 0.03^{* *}$ & $0.10 \pm 0.01$ & $0.14 \pm 0.02$ & $0.33 \pm 0.03^{* * *}$ & $0.26 \pm 0.03^{* * *}$ & $0.13 \pm 0.02$ \\
\hline Failure rate (\%) & $7.65 \pm 3.44$ & $0.00 \pm 0.00$ & ND & ND & $18.44 \pm 4.91$ & $2.13 \pm 1.66$ \\
\hline $\mathrm{RT}$ (ms) & $0.55 \pm 0.03$ & $0.49 \pm 0.04$ & $0.45 \pm 0.01$ & $0.70 \pm 0.08^{*}$ & $0.77 \pm 0.06^{*}$ & $0.62 \pm 0.03$ \\
\hline$\Delta t_{1 / 2}(\mathrm{~ms})$ & $1.26 \pm 0.10^{* *}$ & $1.78 \pm 0.11$ & $2.00 \pm 0.23$ & $1.49 \pm 0.28$ & $111.4 \pm 22.7^{* * *}$ & $592.7 \pm 103.0$ \\
\hline
\end{tabular}

${ }^{a}$ Significance levels were calculated by comparing electrically evoked 5-HT-sensitive EPSC at P1-P5 and P7-P9.

${ }^{b}$ Significance levels were calculated by comparing electrically evoked 5-HT-sensitive and 5-HT-insensitive EPSC at P7-P9.

'Significance levels were calculated by comparing nRT-nVPM IPSC at P1-P5 and P7-P9.

${ }^{*} p<0.05,{ }^{* *} p<0.01,{ }^{* * *} p<0.001 ; N D$, not determined.

nVPM activates both strong nVPM-to-nRT synapses and weaker L6Cx-to-nRT synapses at P7-P9.

\section{nVPM-to-nRT excitatory synapses express functional $5-\mathrm{HT}_{1 \mathrm{~B}} \mathrm{R}$ in young mice}

We have shown earlier that during the first postnatal week the nVPM neurons express transiently $5-\mathrm{HT}_{1 \mathrm{~B}} \mathrm{R}$ mRNA and that $5-\mathrm{HT}_{1 \mathrm{~B}} \mathrm{R}$ activation reduces the release of glutamate at the TC synapse in the L4 barrel cortex (Laurent et al., 2002). We decided to study the effect of 5-HT on the nVPM-evoked EPSCs for two reasons. First, to evaluate the effect of 5-HT on the thalamocortical activity of newborn mice, one needs to know whether 5-HT has the same effect at the nVPM-to-nRT synapses and at the TC synapses or not (Scanziani et al., 1998). Second, especially in younger mice, in which we expect a reduction of the nVPMevoked EPSC amplitude and cannot simply rely on the amplitude to distinguish nVPM-to-nRT and L6Cx-to-nRT EPSCs, the sensitivity to 5 -HT could be used as a criterion to identify the nVPM-to-nRT synapse.

We tested the effect of bath applications of 5-HT $(20 \mu \mathrm{M}$, applied for $4 \mathrm{~min}$ ) on the EPSCs evoked by minimal paired pulse (50 ms interpulse interval) electrical stimulation of the nVPM, between P7 and P9 (Fig. 3). During a 4 min application of $20 \mu \mathrm{M}$ 5-HT, the 5-HT-sensitive EPSCs reached a minimal level at the end of the application and remained stable at a low level for 5-10 min before returning slowly to the control level. A change of EPSC amplitude was considered significant when it reached a value larger than twice the SD in control. Using this criterion, we found an inhibitory effect of $20 \mu \mathrm{M} 5$-HT in a subset of cells (14 of 21). The inhibitory effect was quantified during the maximal stable response to 5 -HT. The inhibition reached $50.9 \pm 5.5 \%$ of control ( $n=6 ; p<0.001)$ (Fig. $3 A)$, it was reversible, and it was associated with an increase of the PPR, which was significantly smaller $(1.10 \pm 0.10 ; n=6 ; p<0.01)$ in control than during the inhibitory effect of 5 -HT $(1.52 \pm 0.15 ; n=6)$, indicating a presynaptic effect of 5-HT. We found that the amplitude of the 5-HT-sensitive nVPM-evoked unitary EPSCs always exceeded $100 \mathrm{pA}(129-1076 \mathrm{pA} ; 543.0 \pm 79.2 \mathrm{pA} ; n=14)$, and it was significantly larger than the amplitude of the 5-HT-insensitive nVPM-evoked unitary EPSCs (22-60 pA; $45.4 \pm 5.7 \mathrm{pA} ; n=7)$. The 5-HT-sensitive and the 5-HT-insensitive EPSCs recorded at P7-P9 also differed significantly by their latency, 10-90\% RT, $\Delta t_{1 / 2}, \mathrm{CV}$, and PPR (Table 1). These results indicate that the large-amplitude (>100 pA) 5-HT-sensitive EPSCs recorded at P7-P9 are nVPM-to-nRT EPSCs. The lack of effect of $20 \mu \mathrm{M}$
5-HT could not simply be attributed to our inability to detect an effect on smaller-amplitude EPSCs for two reasons. First, we also already demonstrated an inhibitory effect of 5-HT on small $(\sim 50$ pA) TC EPSCs recorded in the S1 cortex (Laurent et al., 2002). Second, a significant inhibitory effect of 5-HT was also seen on smaller (195.1 $\pm 47.9 ; n=27)$ nVPM-to-nRT EPSCs recorded in younger (P1-P6) mice (Fig. 4). In a group of cells recorded at P2 and P3 $(n=7)$ with a reversible effect of 5 -HT, the minimal amplitude of the average EPSC reached during the inhibitory effect of $20 \mu \mathrm{M} 5$-HT was $51 \pm 5 \%$ of the control value; in the same cells, the PPR was also increased from $1.48 \pm 0.16$ in control to $1.92 \pm 0.32$ in $5-\mathrm{HT}$.

To confirm the identity of the receptors mediating the inhibitory action of 5-HT, we tested the effect of bath application of the selective $5-\mathrm{HT}_{1 \mathrm{~B}} \mathrm{R}$ antagonist (GR127932) and agonist (CP93129) in young (P7-P9) mice (Fig. 5). The inhibitory effect of a 4 min $5 \mu \mathrm{M} 5$-HT application on the nVPM-evoked EPSCs was fully blocked in the presence of 100 nM GR127932 applied $10 \mathrm{~min}$ before 5-HT. Conversely, the agonist CP93129 (100 nM, $4 \mathrm{~min}$ ), which was tested on large (>200 pA) nVPMevoked minimal EPSCs, systematically (in five of five) mimicked the inhibitory effect of 5-HT, reducing the amplitude of the EPSCs by $31.9 \pm 4.9 \%$, and changing significantly the PPR from $0.96 \pm 0.08$ in control to $1.25 \pm 0.13$ in CP93129 $(p<0.05)$ (data not shown). In agreement with the previous demonstration of a lack of expression of $5-\mathrm{HT}_{1 \mathrm{~B}}$ Rs in the $\mathrm{nVPM}$ of older mice (Laurent et al., 2002), we found no effect of 5-HT (20 $\mu \mathrm{M}, 4 \mathrm{~min}$ ) on the large ( $>200 \mathrm{pA} ; n=5) \mathrm{nVPM}$-evoked EPSCs recorded in the nRT between P18 and P24 (Fig. 5C). Finally, we tested the effect of the agonist CP93129 (100 nM, $4 \mathrm{~min} ; n=5)$ on the first EPSC evoked by a local glutamate pulse in the nVPM and found that the agonist reduced the amplitude of the EPSCs by $56.0 \pm$ $5.9 \%$ (Fig. 6); at the same time, the short-term depression of the EPSCs in the burst was reduced during the inhibitory effect of CP93129, as expected for a presynaptic effect (Fig. 5A). Our results show that the nVPM-to-nRT synapses, expressing functional 5- $\mathrm{HT}_{1 \mathrm{~B}} \mathrm{Rs}$, resemble the TC synapses (Laurent et al., 2002). They also show that the effect of 5-HT can be used as a criterion to distinguish 5-HT-sensitive nVPM-to-nRT EPSCs and 5-HTinsensitive L6Cx-to-nRT EPSCs.

\section{Identification of nRT-to-nVPM GABA ${ }_{A} R$-mediated IPSCs in the newborn mice}

In rodents, the $\mathrm{NPPM}$ contains only glutamatergic relay neurons, and it lacks GABAergic inhibitory interneurons (Tamamaki et al., 

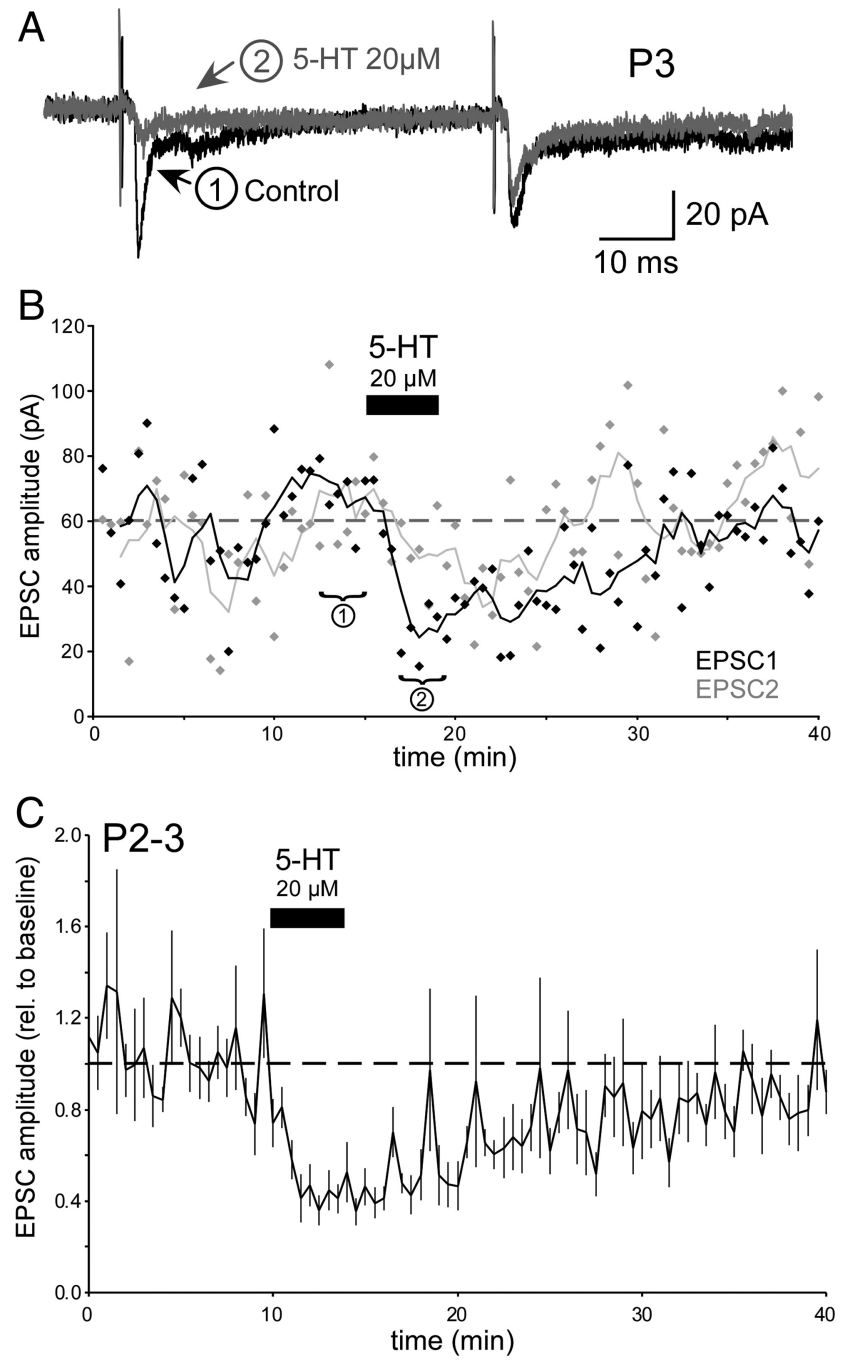

Figure 4. Inhibitory effect of 5-HT on electrically evoked nVPM-to-nRT EPSC in nRT at P2P3.A, Example of a 5-HT-sensitive nVPM-to-nRT EPSC in nRT at P3 ( $-70 \mathrm{mV}$ holding potential). Average $(n=6)$ unitary EPSCs recorded in $\mathrm{nRT}$ in response to paired pulse (50 ms interval) electrical stimulation of nVPM, in control (black trace), and during $20 \mu \mathrm{m} 5$-HT (gray trace). $\boldsymbol{B}$, Time course of inhibitory effect of 5-HT on EPSC1 (black) and EPSC2 (gray) amplitude. Dots are individual responses, and lines are running averages $(n=4)$. In control, EPSC1 and EPSC2 amplitudes were similar, with a PPR (EPSC2/EPSC1) of 1.00. The 5-HT application induced a reduction of EPSC1 amplitude to 53\% of its control value; with EPSC2 being less affected, the PPR increased to 1.23. C, Average (mean $\pm \mathrm{SEM} ; n=7$ cells) time course of the effect of 5 -HT on EPSC1 amplitude of the 5 -HT-sensitive responses recorded at P2-P3.

2003), receiving its main GABAergic input from the nRT (Fuentealba and Steriade, 2005). Somatic whole-cell recordings were made of the $\mathrm{nVPM}$ relay neurons identified by their position in the thalamus, their large soma, and their prominent dendrites. To evoke unitary IPSCs in the nVPM, we used minimal electrical stimulation (see Materials and Methods) of the nRT in the presence of $10 \mu \mathrm{M}$ NBQX and $50 \mu \mathrm{M}$ D-AP-5 to block the disynaptic IPSCs attributable to activation of the TC axons and the monosynaptic EPSCs attributable to activation of the corticothalamic fibers (Golshani et al., 1998; Gentet and Ulrich, 2004; Jacobs et al., 2007).

Recordings were first made in P7-P9 mice (Fig. 7). The lowfrequency $(0.03 \mathrm{~Hz})$ minimal electrical stimulation of the nRT evoked stable single fiber unitary IPSC in the nVPM. The nVPM neurons were voltage clamped near the reversal potential of the EPSCs at $0 \mathrm{mV}$. The minimal $\mathrm{nRT}$ stimulation evoked large-
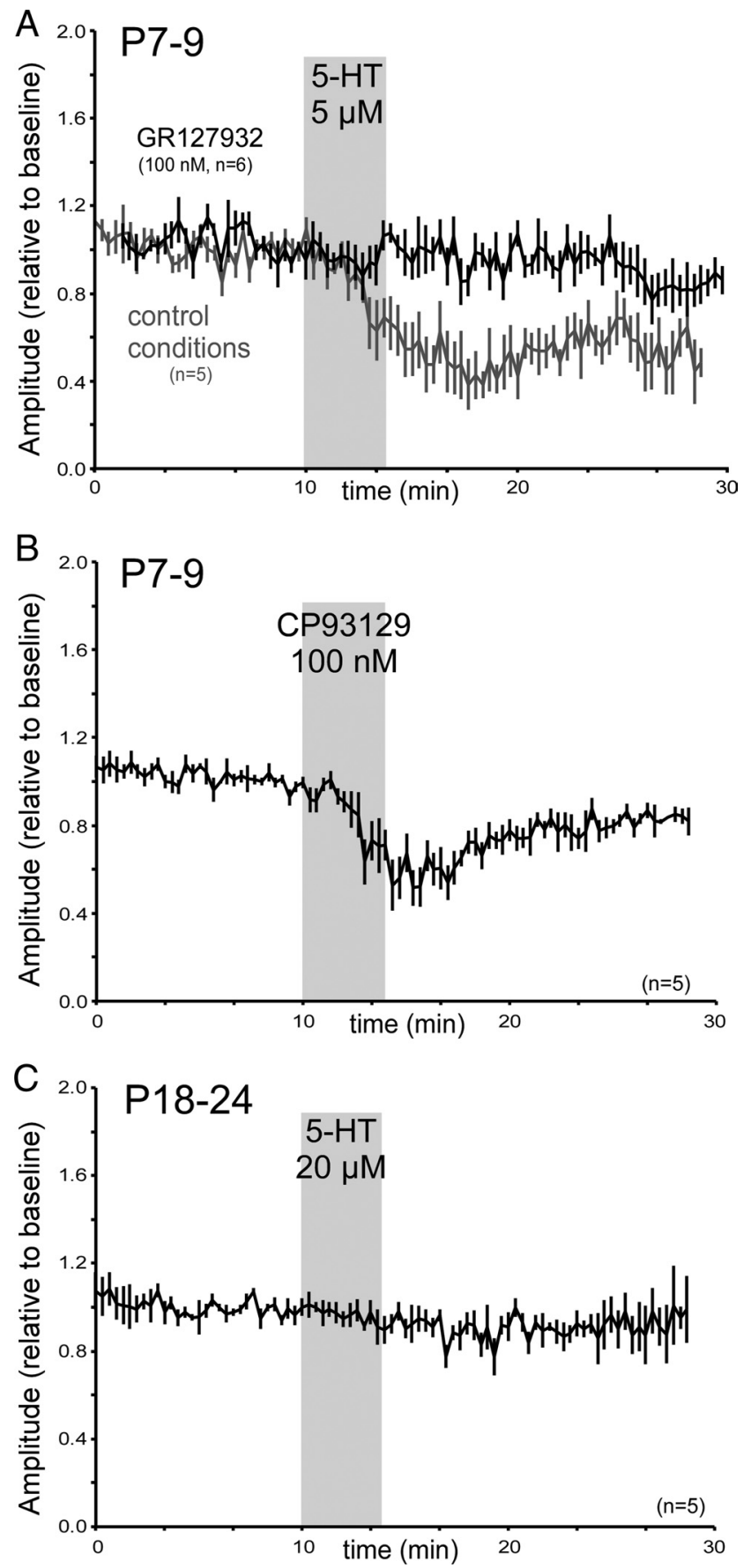

Figure 5. Inhibition of the nVPM-to-nRT EPSC is mediated by $5-\mathrm{HT}_{1 \mathrm{~B}} \mathrm{R}$. $\boldsymbol{A}$, Time course (mean \pm SEM) of the effect of $5 \mu \mathrm{m} 5$-HT on large-amplitude ( $>200 \mathrm{pA}$ ) EPSCs in the absence (gray curve; $n=5$ cells) and presence (black curve; $n=6$ cells) of a $5-\mathrm{HT}_{1 \mathrm{~B}} \mathrm{R}$ antagonist (GR127935, $100 \mu \mathrm{M})$ on the relative nVPM-to-nRT EPSC amplitude evoked by electrical stimulation of nVPM in mice at P7-P9. B, Time course (mean \pm SEM; $n=5$ cells) of the effect of a selective $5-\mathrm{HT}_{1 \mathrm{~B}} \mathrm{R}$ agonist (CP93129, $100 \mathrm{~nm}$ ) on large-amplitude (>200 pA) EPSCs evoked by electrical stimulation of nVPM in mice at P7-P9. C, Time course (mean \pm SEM; $n=5$ ) of the effect of 5-HT (20 $\mu \mathrm{M})$ on large-amplitude ( $>200 \mathrm{pA})$ EPSCs evoked by VPM electrical stimulation, in older (P18-P24) mice.

amplitude $(592.7 \pm 103 \mathrm{pA} ; n=21)$ outward postsynaptic currents with a small percentage of transmission failure (10.27 \pm $2.43 \%)$, a fast $20-80 \%$ RT $(0.62 \pm 0.03 \mathrm{~ms} ; n=21)$, a long duration $\left(\Delta t_{1 / 2}=12.79 \pm 0.49 \mathrm{~ms} ; n=21\right)$, and a short latency (1.77 $\pm 0.06 \mathrm{~ms} ; n=21)$. These outward postsynaptic currents were completely blocked by $10 \mu \mathrm{M}$ gabazine and reversed at 


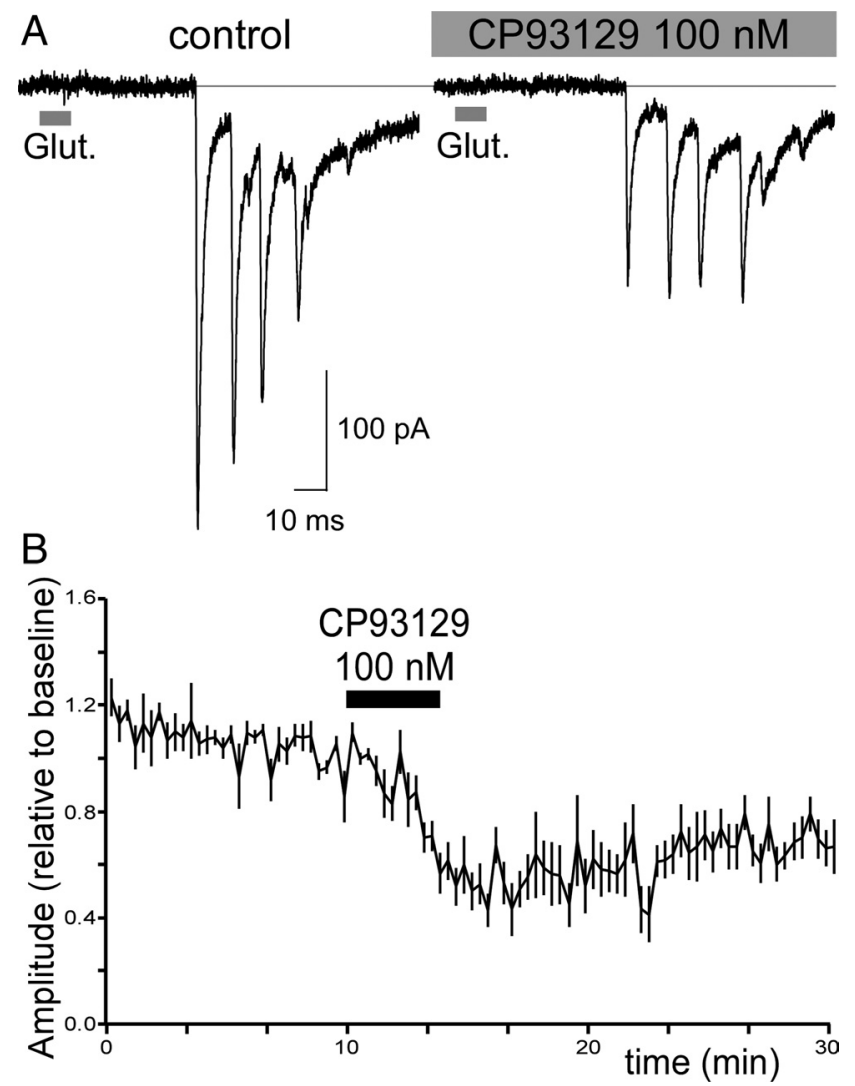

Figure 6. Inhibitory effect of a 5- $\mathrm{HT}_{1 \mathrm{~B}}$ agonist on glutamate-evoked nVPM-to-nRT EPSCs at P7-P9. A, Bursts of fast EPSCs in nRT evoked by a pulse of glutamate (Glut.; $10 \mathrm{~ms}, 100 \mu \mathrm{M}$ ) in nVPM. The bursts of EPSCs are shown in control (left) and during a bath application of $100 \mathrm{nM}$ CP93129 (right). $\boldsymbol{B}$, Time course (mean \pm SEM; $n=5$ cells) of the effect of (P93129 on the amplitude of the first EPSC evoked by a glutamate pulse in nVPM.

$-63.2 \pm 1.3 \mathrm{mV}(n=10)$, the chloride equilibrium potential in our recording conditions. The latency distribution of individual outward postsynaptic currents could be fitted by a simple Gaussian function as expected for a monosynaptic response. These results confirmed that the nRT-to-nVPM outward postsynaptic currents recorded at $0 \mathrm{mV}$ were monosynaptic $\mathrm{GABA}_{\mathrm{A}}$-mediated IPSCs.

\section{Postnatal development of the thalamic inhibitory feedback loop}

The first nVPM-to-nRT (Mitrofanis and Baker, 1993) and corticothalamic (Jacobs et al., 2007) axons reach the nRT at birth, but there has been no systematic study of the EPSC changes with growing from $\mathrm{P} 0$ to $\mathrm{P} 9$. In the $\mathrm{S} 1$ cortex, previous work has shown that the relative contribution of the NMDARs at the TC synapses decreases during the first postnatal week (Crair and Malenka, 1995). The possibility of a similar change at the nVPM-to-nRT synapse was evaluated (Fig. 8). We measured the peak amplitude of the NMDAR-mediated component at $+50 \mathrm{mV}$ and of the AMPAR-mediated component at $-90 \mathrm{mV}$. The nVPM-evoked nVPM-to-nRT EPSCs were identified by their sensitivity to 5-HT at P2-P3 (Fig. 4) and by the amplitude of the AMPA component recorded at $-90 \mathrm{mV}$, exceeding $200 \mathrm{pA}$ at P7-P9. We found that the NMDAR/AMPAR ratio decreased with age from $1.27 \pm 0.27$ $(n=5)$ at P2-P3 to $0.60 \pm 0.07(n=12)$ at P7-P9 $(p<0.01)$. This change was associated with an increase of the AMPAR component amplitude, which was quantified from P1 to P9 (Fig. 9A).

The EPSC AMPA component was recorded at $-90 \mathrm{mV}$. It was identified as nVPM-to-nRT EPSC by examining its sensitivity to
5-HT (Figs. 3, 4). We found that it is possible to record 5-HTsensitive nVPM-to-nRT EPSCs as early as P1, but only one response could be found in six slices. At P2 and later, the yield and amplitude of the EPSCs were increased, and a rapid increase of the EPSC amplitude was found at P6-P7 (Table 1, Fig. 9A). The nVPM-to-nRT EPSC amplitude increased from $145.7 \pm 21.8 \mathrm{pA}$ at P1-P5 (range, 52-366 pA; $n=22$ ) to $543.0 \pm 79.2 \mathrm{pA}$ at P7-P9 (range, 129-1076 pA; $n=14$ ). Moreover, the nVPM-to-nRT EPSCs became more reliable with age (Fig. 9A3, A4), the EPSC failure rate being reduced from $7.65 \pm 3.44 \%$ at P1-P5 $(n=22)$ to 0 at P7-P9 $(n=14)$ and the CV of the EPSC amplitude being reduced from $0.22 \pm 0.03$ at $\mathrm{P} 1-\mathrm{P} 5(n=22)$ to $0.10 \pm 0.01$ at P7-P9 $(n=14)$. These changes were not associated with any significant change of the PPR (Table 1), suggesting postsynaptic modifications.

Previous studies showed that the electrical stimulation of IC can already evoke $\mathrm{GABA}_{\mathrm{A}} \mathrm{R}$-mediated IPSCs in the $\mathrm{nVPM}$ of mice at P3 (Warren and Jones, 1997; Warren et al., 1997). It has also been shown that the amplitude of unitary nRT-to-nVPM IPSCs of older rats (P9-P16) varied widely from 18 to $514 \mathrm{pA}$ (Cox et al., 1997). However, there is no systematic study of the nRT-to-nVPM IPSCs during the first postnatal week; therefore, we studied the changes with age of the $\mathrm{GABA}_{\mathrm{A}}$-mediated nRTto-nVPM IPSCs from P0 to P9 (Table 1, Fig. 9B). We found that the amplitude of the unitary $\mathrm{GABA}_{\mathrm{A}}$-mediated nRT-to-nVPM IPSCs increased from $111.4 \pm 22.7 \mathrm{pA}$ at P1-P5 $(n=18)$ to $592.7 \pm 103.0 \mathrm{pA}$ at $\mathrm{P} 7-\mathrm{P} 9(n=21)$, the increase being relatively rapid at P6-P7 (Fig. 9B2). Moreover, the $\mathrm{GABA}_{\mathrm{A}}$-mediated IPSCs became more reliable with age (Fig. 9B3, B4), with a reduction of the failure rate from $18.44 \pm 4.91 \%$ at P1-P5 $(n=18)$ to $2.13 \pm 1.66 \%$ at $\mathrm{P} 7-\mathrm{P} 9(n=21)$ and a reduction of the CV of the IPSC amplitude from $0.26 \pm 0.03$ at P1-P5 $(n=18)$ to $0.13 \pm$ 0.02 at P7-P9 $(n=21)$. The PPR at $50 \mathrm{~ms}$ was reduced from $1.00 \pm 0.15$ at P1-P5 $(n=16)$ to $0.65 \pm 0.04$ at P7-P9 $(n=17)$, suggesting a presynaptic change of GABA release. Finally, the IPSC duration that is related to the $\mathrm{GABA}_{\mathrm{A}} \mathrm{R}$ characteristics (Zhang et al., 1997; Schofield and Huguenard, 2007) was significantly increased between P1 and P9 (Table 1).

\section{Discussion}

Our results demonstrate that, at P7-P9, the nVPM-to-nRT EPSCs can be distinguished from the L6Cx-to-nRT EPSCs by their large amplitude and by the inhibitory action of 5-HT attributable to the transient expression of presynaptic $5-\mathrm{HT}_{1 \mathrm{~B}} \mathrm{R}$ receptors by the nVPM-to-nRT synapses of the newborn mice. We show that the nVPM-to-nRT EPSCs and nRT-to-nVPM IPSCs are both detected at $\mathrm{P} 1$, their conductance being maintained at $\sim 2$ nS until P5 and that, at P6-P7, there is a rapid and simultaneous increase of the nVPM-to-nRT EPSC and nRT-tonVPM IPSC conductance reaching $\sim 8$ and $\sim 9 \mathrm{nS}$, respectively. We identify for the first time in the newborn mice a functional thalamic inhibitory feedback loop that is under the inhibitory control of 5-HT. Our results suggest that 5-HT could change profoundly the whisker-related activity transmitted to the S1 cortex, thereby influencing the activitydependent development of the cortical synaptic connections before active whisking.

\section{Identification of the EPSCs and IPSCs participating to the thalamic feedback loop}

To activate a single-fiber unitary EPSC in the $\mathrm{nRT}$, we used the minimal stimulation protocol (Fig. 1). We preferred this method over paired recordings to increase the yield of unitary EPSCs 

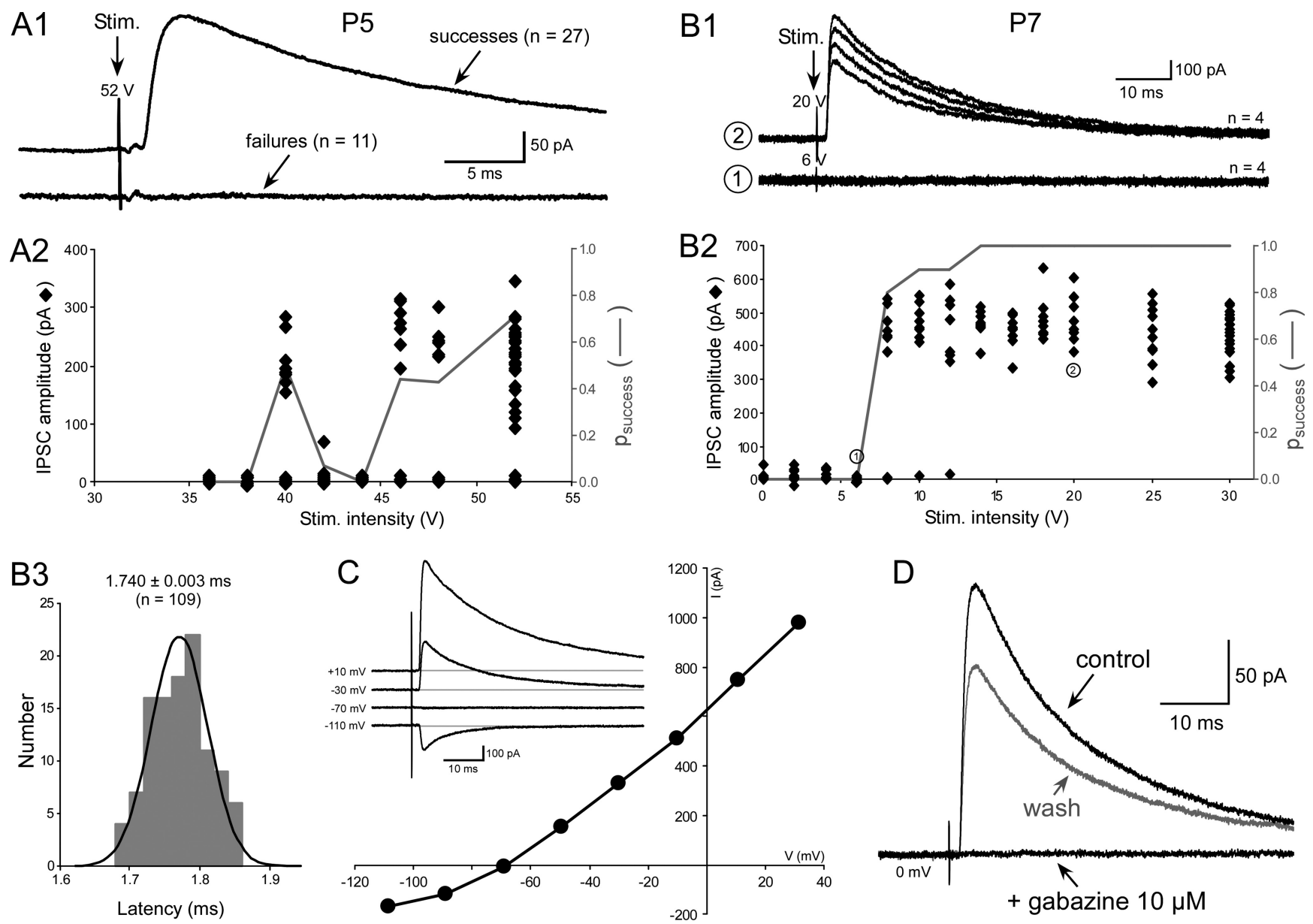

Figure 7. nRT stimulation evokes GABA $R$-mediated nRT-to-nVPM IPSCs. Unitary nRT-to-nVPM IPSCs recorded in newborn mice. Neurons were maintained at $0 \mathrm{mV}$ holding potential, and responses were evoked by minimal electrical stimulation of nRT in presence of $10 \mu \mathrm{m} \mathrm{NBQX}$ and $50 \mu \mathrm{m} \mathrm{D}-\mathrm{AP}-5$. A1, Example of a unitary nRT-to-nVPM IPSCs with failures (11 of 38 ) recorded at P5. Top trace, Average ( $n=27$ ) successful responses evoked by nRT stimulation at $52 \mathrm{~V}$ ( $12 \mathrm{~V}$ above threshold). Bottom trace, Average $(n=11)$ failures of responses evoked by the same stimulation. Failures are confirmed by a short-delay small triphasic afferent volley in all trials. $\boldsymbol{A} 2$, In the same neuron, peak amplitude of individual IPSCs (black diamonds; $n=10-39$ ) and probability of response (gray line) are plotted against stimulation intensity. B1, Example of a unitary nRT-to-nVPM IPSC without failure recorded at P7. Top traces, Superimposed ( $n=4)$ unitary nRT-to-nVPM IPSC evoked by suprathreshold stimulation at $20 \mathrm{~V}$. Bottom traces, Superimposed $(n=4)$ traces evoked by subthreshold stimulation at 6 V. B2, In the same neuron, peak amplitude of individual IPSCs (black diamonds; $n=10-15$ ) and probability of response (gray line) are plotted against stimulation intensity. At 8,10 , and $12 \mathrm{~V}$, responses failures were attributable to a lack of spike discharge by the nVPM neuron. Above $14 \mathrm{~V}$, transmission failures were not seen, and the amplitude of unitary EPSCs was stable near $500 \mathrm{pA}$. B3, The Gaussian distribution of the latency of a monosynaptic unitary nRT-to-nVPM IPSCs ( $1.740 \pm 0.003 \mathrm{~ms} ; n=109)$. C, I-V curve of a unitary nRT-to-nVPM IPSC with a reversal at $-66.3 \mathrm{mV}$. Inset, Average $(n=4-5)$ unitary nRT-to-nVPM IPSCs at $+10,-30$, -70 , and $-110 \mathrm{mV}$. D, Inhibition of a unitary nRT-to-nVPM IPSC by $10 \mu \mathrm{m}$ gabazine. The average $(n=5)$ outward IPSC recorded in control was inhibited by $10 \mu \mathrm{m}$ gabazine and recovered partially after 15 min wash of gabazine (gray trace).

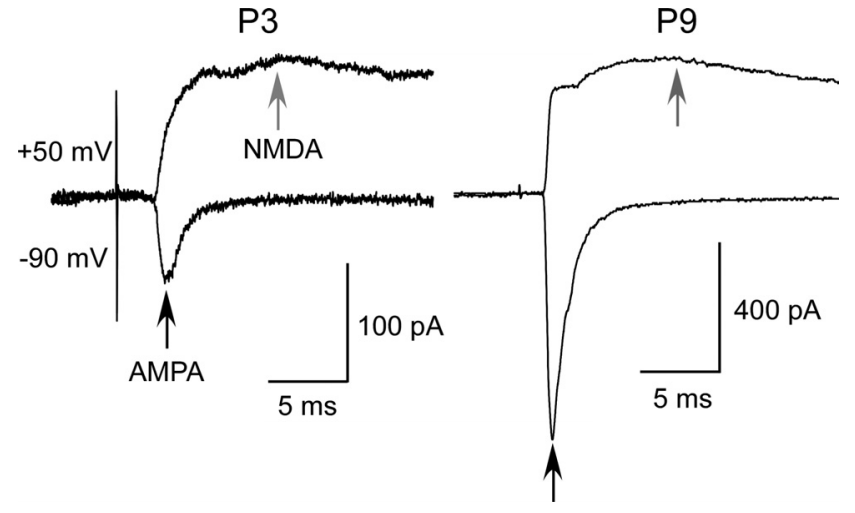

Figure 8. Evolution of glutamatergic receptors at the nVPM-to-nRT synapse. Examples of 5-HTsensitive unitary nVPM-to-nRT EPSCsrecorded at +50 and $-90 \mathrm{mVholding} \mathrm{potentialatP3} \mathrm{(left)} \mathrm{and}$ P9 (right). The AMPA component was measured at the peak of the fast EPSC recorded at $-90 \mathrm{mV}$ to minimize the NMDAR component (black arrow). The NMDA component was measured at $+50 \mathrm{mV}$, $10 \mathrm{~ms}$ after the stimulation artifact to minimize the AMPAR contribution (gray arrow). recorded in the newborn mice. Preliminary experiments were done using focal pulses of glutamate to activate nVPM neurons and to find connected pairs (Gentet and Ulrich, 2003). They were unsuccessful, presumably because there is a lower density of synaptic connections between the nVPM and the nRT during the first postnatal week. In a first series of experiments on P7-P9 mice, we found that the electrical stimulation of the nVPM generates monosynaptic unitary EPSCs with a wide range of amplitude (Fig. 2D2). We also found that a subset (14 of 21) of large-amplitude EPSCs was inhibited by the activation of the $5-\mathrm{HT}_{1 \mathrm{~B}} \mathrm{R}$ (Figs. 3, 5, 6). Importantly, the pulses of glutamate in the nVPM evoked only large-amplitude EPSCs (Fig. 2), which were also inhibited by the application of the $5-\mathrm{HT}_{1 \mathrm{~B}} \mathrm{R}$ agonist CP93129 (Fig. 6), identifying the large 5-HT-sensitive EPSCs evoked by nVPM electrical stimulation or by glutamate pulses as nVPM-to-nRT EPSCs. These results indicate that, in the newborn mice, the activation of $5-\mathrm{HT}_{1 \mathrm{~B}} \mathrm{Rs}$ inhibits the release of glutamate at the nVPM-to-nRT synapses in the thalamus, as found before at the TC synapses in the S1 cortex (Laurent et al., 2002). The absence of an inhibitory 
effect by 5-HT on small-amplitude EPSCs in the young (P7-P9) mice (Fig. 3B) is consistent with a lack of $5-\mathrm{HT}_{1 \mathrm{~B}} \mathrm{R}$ mRNA expression in the layer $6 \mathrm{~S} 1$ cortex of the newborn mice (Laurent et al., 2002), identifying the smaller 5-HT-insensitive EPSCs as possible L6Cx-to-nRT EPSCs. In younger (P1-P6) mice, the amplitude of the EPSCs evoked by electrical stimulation of the nVPM was smaller, but we were still able to find 5-HT-sensitive EPSCs (Fig. 4), indicating therefore that the nVPM-to-nRT EPSCs evoked by the minimal stimulation of the nVPM can be identified by their sensitivity to 5-HT during the entire early (P1-P9) period of development.

The nRT contains an homogeneous population of GABAergic parvalbuminpositive interneurons, and the nVPM receives a dense GABAergic projection from the nRT (Amadeo et al., 2001; Tamamaki et al., 2003), identifying the nRT-to-nVPM synapses as the connection mediating the monosynaptic unitary $\mathrm{GABA}_{\mathrm{A}} \mathrm{R}$-mediated IPSC we recorded in nVPM (Fig. 7).

\section{Change with age of the thalamic inhibitory feedback loop}

The 5-HT-sensitive unitary nVPM-tonRT EPSC displayed several changes with age (P1-P9). First, as suggested by anatomical studies (Mitrofanis and Baker, 1993), the nVPM-to-nRT EPSCs were recorded in the nRT as early as P1, and their conductance increased by a factor of 3.7 from P1-P5 until P7-P9, with an abrupt change at $\mathrm{P} 6-\mathrm{P} 7$ (Fig. 9A). The nVPM-tonRT EPSCs became more reliable with age, as shown by an increase of the probability of release and a reduction of the $\mathrm{CV}$ of the EPSC amplitude. Second, the nVPM-to-nRT synapse was relatively immature at $\mathrm{P} 1$, with a relatively stronger expression of the NMDAR in P1-P5 mice than in P7-P9 mice (Fig. 8), as found at the same age at the thalamocortical synapse in the barrel cortex (Crair and Malenka, 1995; Lu et al., 2001). The efficacy of the monosynaptic $\mathrm{GABA}_{\mathrm{A}^{-}}$ mediated nRT-to-nVPM IPSCs was also increased with age, with both the conductance of the unitary IPSCs and the probability of GABA release being increased (Fig. 9B). The driving force of the PSCs was maintained constant for all recordings; therefore, the change of the PSC amplitude can only be attributed to an increase of the synaptic conductance. Our results show that functional nRT-mediated IPSCs are already present at birth in the nVPM of the mouse as in the rat (Leamey and Ho, 1998). Interestingly, both the nRT-to-nVPM IPSCs and the nVPM-to-nRT EPSCs underwent a rapid increase of their amplitude and probability of success at P6-P7. In conclusion, both excitatory nVPMto-nRT and inhibitory nRT-to-nVPM synapses of the thalamic
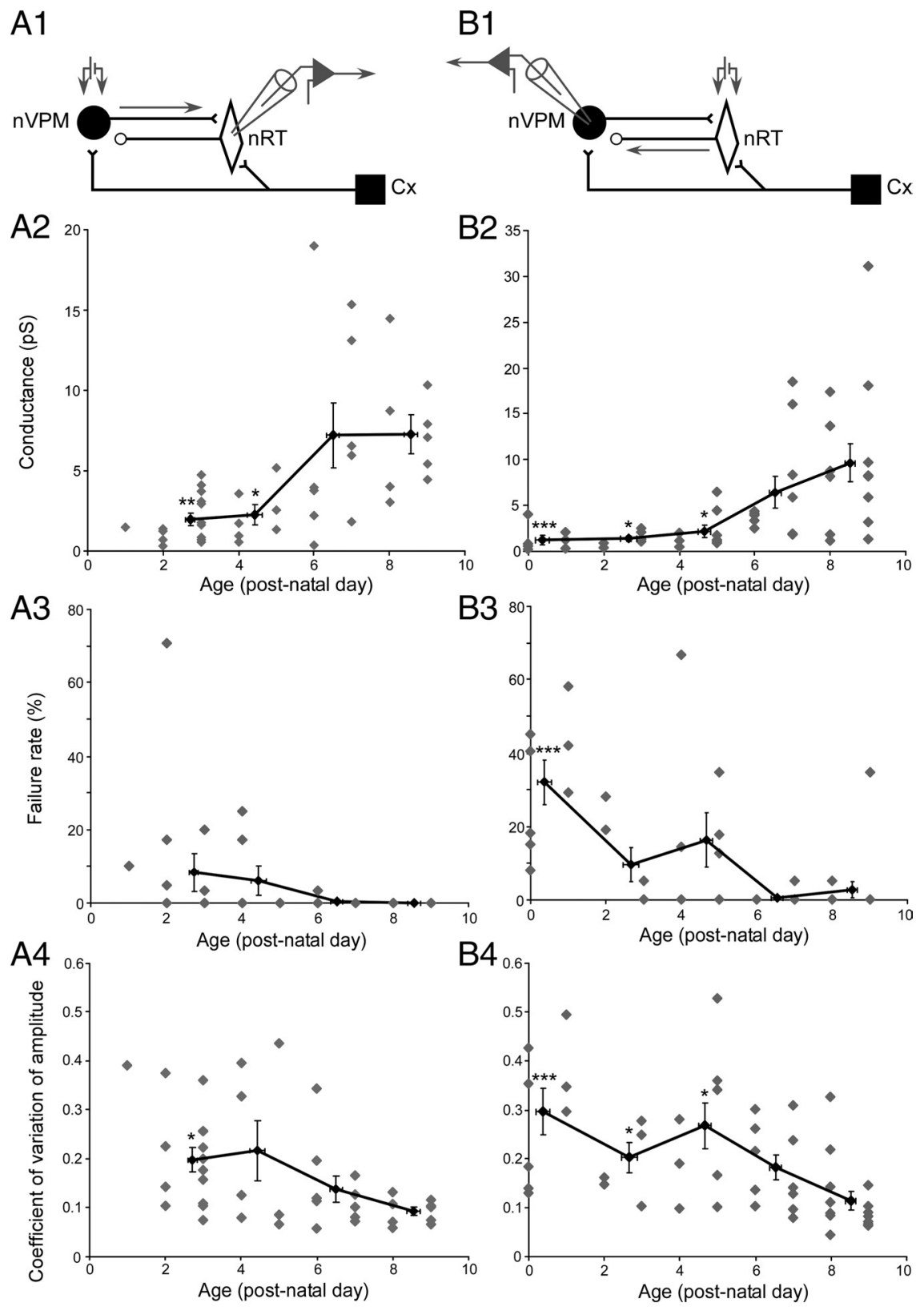

Figure 9. Evolution with age of the nVPM-to-nRT EPSCs and nRT-to-nVPM IPSCS. A1-A4, Changes with age (P1-P9) of 5-HT-sensitive unitary nVPM-to-nRT EPSCs evoked by electrical stimulation of nVPM. A1, Circuit diagram. A2-A4, The conductance $(\boldsymbol{A 2})$, failure rate $(\boldsymbol{A} \boldsymbol{3})$, and coefficient of variation ( $\boldsymbol{A} 4)$ of the unitary nVPM-to-nRT EPSCs are plotted against age. Individual data (dots) and mean \pm SEM calculated for periods of $2 \mathrm{~d}(\mathrm{P} 2-\mathrm{P3}$, P4 -P5, P6 -P7, and P8 -P9) are plotted together. B1-B4, Changes with age (P0 -P9) of unitary nRT-to-nVPM IPSCs evoked by electrical stimulation of nRT in the presence of $10 \mu \mathrm{M}$ NBQX and $50 \mu \mathrm{M} \mathrm{D}-A \mathrm{P}-5 . \mathbf{B 1}$, Circuit diagram. $\boldsymbol{B 2}-\boldsymbol{B} 4$, The amplitude (B2), failure rate $(\boldsymbol{B} 3)$, and coefficient of variation $(\boldsymbol{B} 4)$ of the nRT-to-nVPM IPSCs are plotted versus the age. Individual data (dots) and mean \pm SEM calculated for periods of $2 \mathrm{~d}$ (P0-P1, $P 2-P 3, P 4-P 5, P 6-P 7$, and P8 $-P 9)$ are plotted together. The results at $P 8-P 9$ were taken as reference to calculate the statistical significance $\left.{ }^{*} p<0.05,{ }^{* *} p<0.01,{ }^{* * *} p<0.001\right)$. Cx, Cortex.

feedback loop are functional at P1, and they undergo a rapid synchronized increase at P6-P7. Interestingly, the synapses of the feedforward inhibitory circuit of the barrel cortex undergo also a rapid synchronized increase, allowing the recruitment of the feedforward cortical inhibition by the thalamocortical input at P6-P7 (Daw et al., 2007). Such a coordinated enhancement of the synaptic transmission in the thalamic feedback and cortical feedforward loops suggest that the thalamus generates an instructive signal for the rapid enhancement of the nVPM-to-nRT and TC synaptic connections. 
In newborn (P1-P8) rats, spontaneous spindles have been recorded in the $\mathrm{S} 1$ cortex during spontaneous muscle twitches. They are associated with a correlated activity in the nVPM, and their intrinsic frequency is unaffected by cortical applications of $\mathrm{GABA}_{\mathrm{A}} \mathrm{R}$ antagonists, suggesting that the spindles are generated by subcortical circuits (Khazipov et al., 2004; Minlebaev et al., 2007). In the adult, the sleep spindles are generated by the nVPM-nRT loop (Steriade, 2005). Our results show that, in newborn mice, the synaptic connections of the thalamic nVPMnRT loop are already functional. Whether this functional loop contributes to the generation of cortical spindles in newborn mice needs additional studies. In particular, the polarity of the $\mathrm{GABA}_{\mathrm{A}} \mathrm{R}$-mediated postsynaptic responses, which depends both on $\mathrm{RMP}$ and $\mathrm{E}_{\mathrm{Cl}}^{-}$and on the action potential threshold ( $\left.\mathrm{AP}_{\text {thresh }}\right)$, should be investigated in the newborn mice. All three parameters ( $\mathrm{RMP}, E_{\mathrm{Cl}}^{-}$, and $\mathrm{AP}_{\text {thresh }}$ ) need to be investigated in conditions that do not affect their measurement (Tyzio et al., 2003; Rheims et al., 2008). In conclusion, our results suggest that the nVPM-to-nRT inhibitory feedback loop may stand as an important checkpoint to generate spindles in the thalamocortical circuit before active whisking. Further work will be needed to study whether this thalamic circuit actually generates spindles in the neonate and whether the mechanisms of spindle generation are the same in the neonate and in the adult.

Our results also suggest that the development of the thalamic feedback circuit and the refinement of the highly organized axonal and dendritic arborizations (Pinault and Deschenes, 1998; Desîlets-Roy et al., 2002) are probably also under the control of the spontaneous and whisker-generated neuronal activity. Neurotransmitter receptors already identified as critical for the development of the primary sensory maps, such as the NMDARs (Inan and Crair, 2007), GABA $\mathrm{R}$ (Hensch, 2005), and 5- $\mathrm{HT}_{1 \mathrm{~B}} \mathrm{Rs}$ (Gaspar et al., 2003), are probably playing important role in the thalamus. Our results have shown a relative downregulation of the NMDAR expression at the nVPM-to-nRT synapse after the first postnatal week. Therefore, it would be of interest to examine whether the thalamic feedback loop undergoes a critical period of plasticity as found in the S1 cortex (Crair and Malenka, 1995). We also found that the release of glutamate at the nVPM-to-nRT synapses is controlled by the $5-\mathrm{HT}_{1 \mathrm{~B}} \mathrm{Rs}$ of the newborn mice, raising the possibility that the abnormal barrel field found with excessive levels of 5-HT (Cases et al., 1996; Salichon et al., 2001) may be associated with abnormal spindles in the newborn mice and anatomical changes in the thalamic neuronal circuits.

Our results show also that the efficacy of synaptic transmission in the thalamic nVPM-nRT feedback loop is strong at the end of the first postnatal week, suggesting that it may already ensure a relatively good temporal coding of the sensory information (Hartings et al., 2003). The $\mathrm{GABA}_{\mathrm{A}}$-mediated IPSC will undergo more changes, such as a reduction of their duration, later in development (Warren and Jones, 1997; Huntsman and Huguenard, 2000; Peden et al., 2008), suggesting that the thalamic inhibitory feedback loop has not yet reached its adult stage at the end of the first postnatal week.

\section{References}

Amadeo A, Ortino B, Frassoni C (2001) Parvalbumin and GABA in the developing somatosensory thalamus of the rat: an immunocytochemical ultrastructural correlation. Anat Embryol (Berl) 203:109-119.

Belford GR, Killackey HP (1979a) Vibrissae representation in subcortical trigeminal centers of the neonatal rat. J Comp Neurol 183:305-321.

Belford GR, Killackey HP (1979b) The development of vibrissae represen- tation in subcortical trigeminal centers of the neonatal rat. J Comp Neurol 188:63-74.

Belford GR, Killackey HP (1980) The sensitive period in the development of the trigeminal system of the neonatal rat. J Comp Neurol 193:335-350.

Bourassa J, Pinault D, Deschênes M (1995) Corticothalamic projections from the cortical barrel field to the somatosensory thalamus in rats: a single-fibre study using biocytin as an anterograde tracer. Eur J Neurosci 7:19-30.

Carvell GE, Simons DJ (1996) Abnormal tactile experience early in life disrupts active touch. J Neurosci 16:2750-2757.

Cases O, Vitalis T, Seif I, De Maeyer E, Sotelo C, Gaspar P (1996) Lack of barrels in the somatosensory cortex of monoamine oxidase A-deficient mice: role of a serotonin excess during the critical period. Neuron 16:297-307.

Cox CL, Huguenard JR, Prince DA (1997) Nucleus reticularis neurons mediate diverse inhibitory effects in thalamus. Proc Natl Acad Sci U S A 94:8854-8859.

Crair MC (1999) Neuronal activity during development: permissive or instructive? Curr Opin Neurobiol 9:88-93.

Crair MC, Malenka RC (1995) A critical period for long-term potentiation at thalamocortical synapses. Nature 375:325-328.

Datwani A, Iwasato T, Itohara S, Erzurumlu RS (2002a) Lesion-induced thalamocortical axonal plasticity in the $\mathrm{S} 1$ cortex is independent of NMDA receptor function in excitatory cortical neurons. J Neurosci 22:9171-9175.

Datwani A, Iwasato T, Itohara S, Erzurumlu RS (2002b) NMDA receptordependent pattern transfer from afferents to postsynaptic cells and dendritic differentiation in the barrel cortex. Mol Cell Neurosci 21:477-492.

Daw MI, Ashby MC, Isaac JT (2007) Coordinated developmental recruitment of latent fast spiking interneurons in layer IV barrel cortex. Nat Neurosci 10:453-461.

Desîlets-Roy B, Varga C, Lavallée P, Deschênes M (2002) Substrate for cross-talk inhibition between thalamic barreloids. J Neurosci 22:RC218(1-4).

Erzurumlu RS, Kind PC (2001) Neural activity: sculptor of "barrels" in the neocortex. Trends Neurosci 24:589-595.

Feldman DE, Nicoll RA, Malenka RC, Isaac JT (1998) Long-term depression at thalamocortical synapses in developing rat somatosensory cortex. Neuron 21:347-357.

Fuentealba P, Steriade M (2005) The reticular nucleus revisited: intrinsic and network properties of a thalamic pacemaker. Prog Neurobiol 75:125-141.

Gaspar P, Cases O, Maroteaux L (2003) The developmental role of serotonin: news from mouse molecular genetics. Nat Rev Neurosci 4:1002-1012.

Gentet LJ, Ulrich D (2003) Strong, reliable and precise synaptic connections between thalamic relay cells and neurones of the nucleus reticularis in juvenile rats. J Physiol 546:801-811.

Gentet LJ, Ulrich D (2004) Electrophysiological characterization of synaptic connections between layer VI cortical cells and neurons of the nucleus reticularis thalami in juvenile rats. Eur J Neurosci 19:625-633.

Golshani P, Warren RA, Jones EG (1998) Progression of change in NMDA, non-NMDA, and metabotropic glutamate receptor function at the developing corticothalamic synapse. J Neurophysiol 80:143-154.

Hannan AJ, Blakemore C, Katsnelson A, Vitalis T, Huber KM, Bear M, Roder J, Kim D, Shin HS, Kind PC (2001) PLC-betal, activated via mGluRs, mediates activity-dependent differentiation in cerebral cortex. Nat Neurosci 4:282-288.

Hartings JA, Temereanca S, Simons DJ (2003) Processing of periodic whisker deflections by neurons in the ventroposterior medial and thalamic reticular nuclei. J Neurophysiol 90:3087-3094.

Hensch TK (2005) Critical period plasticity in local cortical circuits. Nat Rev Neurosci 6:877-888.

Huberman AD, Feller MB, Chapman B (2008) Mechanisms underlying development of visual maps and receptive fields. Annu Rev Neurosci 31:479-509.

Huntsman MM, Huguenard JR (2000) Nucleus-specific differences in GABA(A)-receptor-mediated inhibition are enhanced during thalamic development. J Neurophysiol 83:350-358.

Inan M, Crair MC (2007) Development of cortical maps: perspectives from the barrel cortex. Neuroscientist 13:49-61.

Inan M, Lu HC, Albright MJ, She WC, Crair MC (2006) Barrel map devel- 
opment relies on protein kinase A regulatory subunit II beta-mediated cAMP signaling. J Neurosci 26:4338-4349.

Iwasato T, Erzurumlu RS, Huerta PT, Chen DF, Sasaoka T, Ulupinar E, Tonegawa S (1997) NMDA receptor-dependent refinement of somatotopic maps. Neuron 19:1201-1210.

Iwasato T, Datwani A, Wolf AM, Nishiyama H, Taguchi Y, Tonegawa S, Knöpfel T, Erzurumlu RS, Itohara S (2000) Cortex-restricted disruption of NMDAR1 impairs neuronal patterns in the barrel cortex. Nature 406:726-731.

Iwasato T, Inan M, Kanki H, Erzurumlu RS, Itohara S, Crair MC (2008) Cortical adenylyl cyclase 1 is required for thalamocortical synapse maturation and aspects of layer IV barrel development. J Neurosci 28:5931-5943.

Jacobs EC, Campagnoni C, Kampf K, Reyes SD, Kalra V, Handley V, Xie YY, Hong-Hu Y, Spreur V, Fisher RS, Campagnoni AT (2007) Visualization of corticofugal projections during early cortical development in a tauGFP-transgenic mouse. Eur J Neurosci 25:17-30.

Jeanmonod D, Rice FL, Van der Loos H (1981) Mouse somatosensory cortex: alterations in the barrel field following receptor injury at different early postnatal ages. Neuroscience 6:1503-1535.

Khazipov R, Sirota A, Leinekugel X, Holmes GL, Ben-Ari Y, Buzsáki G (2004) Early motor activity drives spindle bursts in the developing somatosensory cortex. Nature 432:758-761.

Killackey HP, Belford GR (1979) The formation of afferent patterns in the somatosensory cortex of the neonatal rat. J Comp Neurol 183:285-303.

Landers M, Philip Zeigler H (2006) Development of rodent whisking: trigeminal input and central pattern generation. Somatosens Mot Res 23:1-10.

Laurent A, Goaillard JM, Cases O, Lebrand C, Gaspar P, Ropert N (2002) Activity-dependent presynaptic effect of serotonin 1B receptors on the somatosensory thalamocortical transmission in neonatal mice. J Neurosci 22:886-900.

Leamey CA, Ho SM (1998) Afferent arrival and onset of functional activity in the trigeminothalamic pathway of the rat. Brain Res Dev Brain Res 105:195-207.

Lee LJ, Iwasato T, Itohara S, Erzurumlu RS (2005) Exuberant thalamocortical axon arborization in cortex-specific NMDAR1 knockout mice. J Comp Neurol 485:280-292.

Lee SH, Land PW, Simons DJ (2007) Layer- and cell-type-specific effects of neonatal whisker-trimming in adult rat barrel cortex. J Neurophysiol 97:4380-4385.

Li Y, Erzurumlu RS, Chen C, Jhaveri S, Tonegawa S (1994) Whisker-related neuronal patterns fail to develop in the trigeminal brainstem nuclei of NMDAR1 knockout mice. Cell 76:427-437.

Liu XB, Bolea S, Golshani P, Jones EG (2001) Differentiation of corticothalamic and collateral thalamocortical synapses on mouse reticular nucleus neurons by EPSP amplitude and AMPA receptor subunit composition. Thalamus Relat Syst 1:15-29.

Lu HC, Gonzalez E, Crair MC (2001) Barrel cortex critical period plasticity is independent of changes in NMDA receptor subunit composition. Neuron 32:619-634.

Minlebaev M, Ben-Ari Y, Khazipov R (2007) Network mechanisms of spindle-burst oscillations in the neonatal rat barrel cortex in vivo. J Neurophysiol 97:692-700.

Minlebaev M, Ben-Ari Y, Khazipov R (2009) NMDA receptors pattern early activity in the developing barrel cortex in vivo. Cereb Cortex 19:688-696.

Mitrofanis J, Baker GE (1993) Development of the thalamic reticular and perireticular nuclei in rats and their relationship to the course of growing corticofugal and corticopetal axons. J Comp Neurol 338:575-587.
Peden DR, Petitjean CM, Herd MB, Durakoglugil MS, Rosahl TW, Wafford K, Homanics GE, Belelli D, Fritschy JM, Lambert JJ (2008) Developmental maturation of synaptic and extrasynaptic GABAA receptors in mouse thalamic ventrobasal neurones. J Physiol 586:965-987.

Pinault D, Deschênes M (1998) Anatomical evidence for a mechanism of lateral inhibition in the rat thalamus. Eur J Neurosci 10:3462-3469.

Rebsam A, Seif I, Gaspar P (2005) Dissociating barrel development and lesion-induced plasticity in the mouse somatosensory cortex. J Neurosci 25:706-710.

Rema V, Armstrong-James M, Ebner FF (2003) Experience-dependent plasticity is impaired in adult rat barrel cortex after whiskers are unused in early postnatal life. J Neurosci 23:358-366.

Rheims S, Minlebaev M, Ivanov A, Represa A, Khazipov R, Holmes GL, Ben-Ari Y, Zilberter Y (2008) Excitatory GABA in rodent developing neocortex in vitro. J Neurophysiol 100:609-619.

Salichon N, Gaspar P, Upton AL, Picaud S, Hanoun N, Hamon M, De Maeyer E, Murphy DL, Mossner R, Lesch KP, Hen R, Seif I (2001) Excessive activation of serotonin (5-HT) $1 \mathrm{~B}$ receptors disrupts the formation of sensory maps in monoamine oxidase a and 5-ht transporter knock-out mice. J Neurosci 21:884-896.

Scanziani M, Gähwiler BH, Charpak S (1998) Target cell-specific modulation of transmitter release at terminals from a single axon. Proc Natl Acad Sci U S A 95:12004-12009.

Schofield CM, Huguenard JR (2007) GABA affinity shapes IPSCs in thalamic nuclei. J Neurosci 27:7954-7962.

Shoykhet M, Land PW, Simons DJ (2005) Whisker trimming begun at birth or on postnatal day 12 affects excitatory and inhibitory receptive fields of layer IV barrel neurons. J Neurophysiol 94:3987-3995.

Simons DJ, Land PW (1987) Early experience of tactile stimulation influences organization of somatic sensory cortex. Nature 326:694-697.

Steriade M (2005) Sleep, epilepsy and thalamic reticular inhibitory neurons. Trends Neurosci 28:317-324.

Tamamaki N, Yanagawa Y, Tomioka R, Miyazaki J, Obata K, Kaneko T (2003) Green fluorescent protein expression and colocalization with calretinin, parvalbumin, and somatostatin in the GAD67-GFP knock-in mouse. J Comp Neurol 467:60-79.

Tyzio R, Ivanov A, Bernard C, Holmes GL, Ben-Ari Y, Khazipov R (2003) Membrane potential of CA3 hippocampal pyramidal cells during postnatal development. J Neurophysiol 90:2964-2972.

Van der Loos H, Woolsey TA (1973) Somatosensory cortex: structural alterations following early injury to sense organs. Science 179:395-398.

Warren RA, Jones EG (1997) Maturation of neuronal form and function in a mouse thalamo-cortical circuit. J Neurosci 17:277-295.

Warren RA, Golshani P, Jones EG (1997) GABA(B)-receptor-mediated inhibition in developing mouse ventral posterior thalamic nucleus. J Neurophysiol 78:550-553.

Watson RF, Abdel-Majid RM, Barnett MW, Willis BS, Katsnelson A, Gillingwater TH, McKnight GS, Kind PC, Neumann PE (2006) Involvement of protein kinase A in patterning of the mouse somatosensory cortex. J Neurosci 26:5393-5401.

Woolsey TA, Van der Loos H (1970) The structural organization of layer IV in the somatosensory region (SI) of mouse cerebral cortex. The description of a cortical field composed of discrete cytoarchitectonic units. Brain Res 17:205-242.

Zhang SJ, Huguenard JR, Prince DA (1997) GABAA receptor-mediated $\mathrm{Cl}^{-}$currents in rat thalamic reticular and relay neurons. J Neurophysiol $78: 2280-2286$. 